\title{
Environmental monitoring and urban phytodesign in ensuring the radioecological safety of urban buildings
}

\author{
Alena Gorodnichaya ${ }^{1}$, Alexandr Melchenko ${ }^{1, *}$ \\ ${ }^{1}$ Kuban State Agrarian University, Kalinina str., 13, 350044, Krasnodar, Russia
}

\begin{abstract}
The purpose of this paper is to study the migration and accumulation of ${ }^{90} \mathrm{Sr}$ in vegetative and generative organs of plants: golden currant (Ríbes aureum) and cherry plum (Prunus cerasifera Ehrh). Research objectives: 1) ${ }^{90} \mathrm{SrCl}_{2}$ is artificially deposited on the soil, precipitation imitation (field experiments); 2) planting plants: Prunus cerasifera Ehrh and Ríbes aureum to the soil artificially contaminated with ${ }^{90} \mathrm{SrCl}_{2}$;3) cultivation and monitoring of the studied plants in the soil artificially contaminated with ${ }^{90} \mathrm{SrCl}_{2}$. The contamination level of the experimental area was $500 \mathrm{MBq} / \mathrm{m}^{2}$. The possibilities of tree and shrub plant forms (Prunus cerasifera Ehrh; Ríbes aureum) to accumulate ${ }^{90} \mathrm{Sr}$ in their vegetative and generative organs were studied. The activity of the beta-emitting radionuclide in the counting samples was measured using the "Progress" software on the Multi-purpose spectrometric complex "Gamma Plus" device (beta path). As a result of research, the accumulation of radionuclides in both studied plants was found. In 2016, the difference in the content of ${ }^{90} \mathrm{Sr}$ between cherry plum and golden currant in bark, wood, leaves, and fruits was 1.6, 1.5, 1.8, and 2.0 times, respectively. Experimental data can be used in the environmental monitoring of the radiation situation in urban areas of the territories allocated for the construction of public, residential buildings and structures, to be the basis for further advanced research in the designated area.
\end{abstract}

\section{Introduction}

Radioactive contamination of territories can occur as a result of various causes, one of them is an anthropogenic factor. The widespread use of nuclear energy in various sectors of the national economy, the extraction and processing of mineral resources, the disposal of radioactive waste, the testing of nuclear weapons, the storage and regeneration of spent nuclear fuel, the accidents at nuclear power plants lead to environmental pollution [1-7]. Researches in the field of agriculture, aimed at using radioactively contaminated lands for possible growing of agricultural crops, searching for ways to reduce the content of radionuclides in the generative organs of plants were carried out earlier and continue to be carried out [8-12]. There are a lot of scientific works related to the monitoring of areas adjacent to nuclear power plants $[13,14]$. Some plant species have a high potential for use

\footnotetext{
* Corresponding author: alexkuban59@mail.ru
} 
as a monitoring of radionuclide contamination [15-17]. At the same time, the topic of environmental monitoring in the radiation safety of urban buildings has not been studied enough. The purpose of this work is to study the migration and accumulation of ${ }^{90} \mathrm{Sr}$ in vegetative and generative organs of plants: golden currant (Ríbes aureum) and cherry plum (Prunus cerasifera Ehrh). The studies were performed in the field during 2010-2016. ${ }^{90} \mathrm{SrCl}_{2}$ is artificially introduced onto the soil surface.

The novelty of research is the possibility of performing environmental monitoring of the radiation safety of urban buildings based on the use of golden currant (Ríbes aureum) and cherry plum (Prunus cerasifera Ehrh). For a short period of time, the proposed monitoring option can provide an answer - does the test piece of land pose a threat to human life and health in terms of radioactive contamination or not. For the construction of residential, public and industrial buildings, the customer is assigned with a certain land area, which must be comprehensively studied by specialists. Engineering surveys are conducted on this area, including local monitoring of various environmental components [18].

\section{Materials and methods}

Investigations were carried out in the field on leached, low humus, and ultra black soil $[19,20]$. All works were performed according to the field experimental methodology [1] with full homogeneity of conditions. For artificial contamination of the surface of the soil

${ }^{90} \mathrm{SrCl}_{2}$ was used. The contamination of the experimental plot was $500 \mathrm{MBq} / \mathrm{m}^{2}$. Prunus cerasifera Ehrh and Ríbes aureum were studied cultures at the experimental plot: the experimental plot was laid in 2008. There were 2 types of plots on the site. First variant Prunus cerasifera Ehrh seedlings (6 pcs.) were planted in radioactively contaminated soil. The seedling environment zone was $6 \times 4 \mathrm{~m}$. Second variant - Ríbes aureum bushes $(6 \mathrm{pcs}$.) were planted in the radioactively contaminated soil. At the ends of the rows of plots, protective plants were placed - by 2 pcs. [1]. The seedling environment zone was $4 \times 4 \mathrm{~m}$. Both variants were repeated 6 times. Sampling of the studied plants was made in 2010, 2014-2016. The plants were divided into organs and parts, dried in a drying cabinet at a temperature of $1050^{\circ} \mathrm{C}$, weighed and grinded in mills MRP-1 or EM-ZA.

Tests of grinded products on the basis of radioactive contamination were performed on the Multi-purpose spectrometric complex "Gamma Plus" device according to the method for measuring the activity of beta-emitting radionuclides in counting samples, using the "Progress" software. The methodology was developed by SC VNIIFTRI and approved by Gosstandart of Russia on 05.05.1996. This methodology is fundamental in determining the activity values of beta-emitting radionuclides in a counting sample and allows calculating the error of each measurement. To register beta radiation from a counting sample, a beta spectrometric path with a scintillation detection unit (SDU) was used. Special aluminum cuvettes were used to expose counting samples (Multi-purpose spectrometric complex "Gamma Plus", 1995). When monitoring the content of strontium-90 in soils and plants, methodical instructions were used (Guidelines for determining the content of strontium-90 and cesium-137 in soils and plants, CINAO, 1985), GOST R 50801-95, and also OST R 10070-95 Soils. The methodology for determination of strontium-90 in the soils of farmland (OST R 10070-95). The obtained results were processed by the methods of mathematical statistics by B.A. Dospekhov [1].

\section{Results}

The content of ${ }^{90} \mathrm{Sr}$ was determined in various organs and parts of the studied plants. The difference in the radionuclide content in the bark of the cherry plum (Prunus cerasifera 
Ehrh) and the golden currant (Ríbes aureum) was 2.8 times in 2010, 1.6 times in 2016. In the initial period of research, both plants have a fairly close contact of the root system with a radionuclide located in the upper soil layer. Due to the larger volume of the root system and the volume of aboveground mass, cherry plum has a greater accumulation of nuclide in the initial period of research. Later, in the process of plant growth and development, the root system gradually goes deep into the soil, which undoubtedly influenced the nuclide content in the bark of the cherry plum. This is confirmed by the dynamics of accumulation of ${ }^{90} \mathrm{Sr}$ in the bark; it tends to decrease. The dynamics of nuclide accumulation in the bark of the golden currant is completely different. Due to the fact that the root system is much longer in the upper soil layer, where ${ }^{90} \mathrm{Sr}$ is located, its accumulation in the bark occurs more intensively: for 6 years of research, accumulation in the bark has changed 2.7 times, whereas in cherry plum - 1.6 times (Fig. 1).

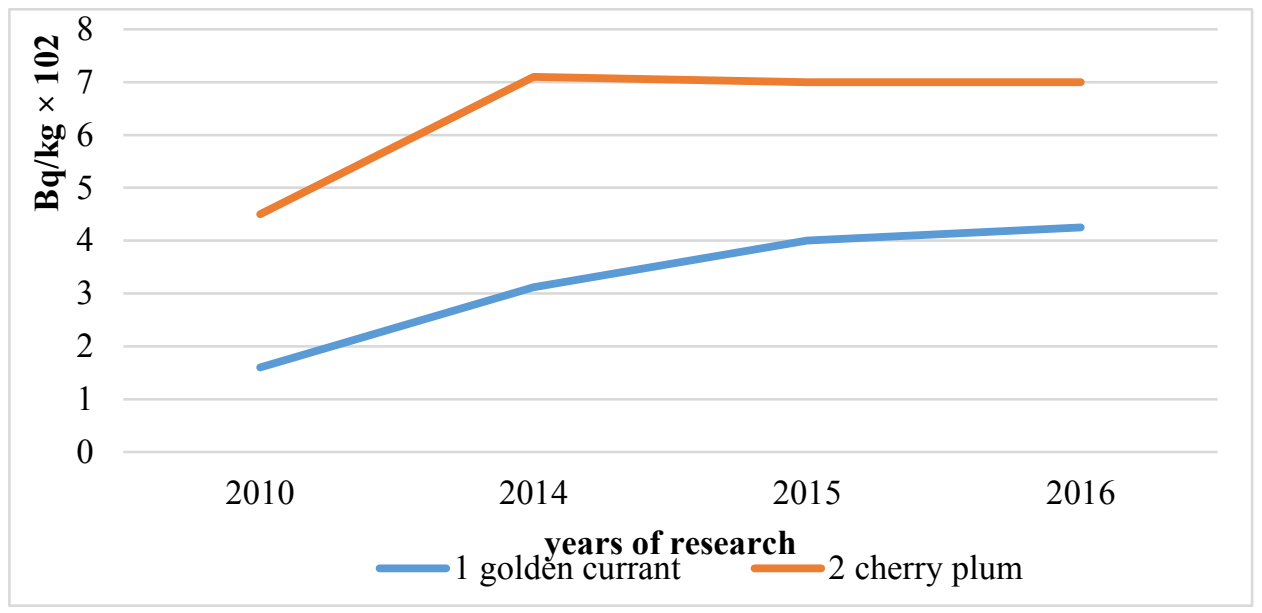

Fig. 1. Content of ${ }^{90} \mathrm{Sr}$ in the bark of the studied plants.

The difference in the accumulation of radionuclides in the bark between cherry plum and golden currant was 2.8, 2.3, 1.75, and 1.6 times in 2010, 2014, 2015, and 2016, respectively.

In the process of studying the accumulation of ${ }^{90} \mathrm{Sr}$ in plants, its content in the wood was determined (Fig. 2).

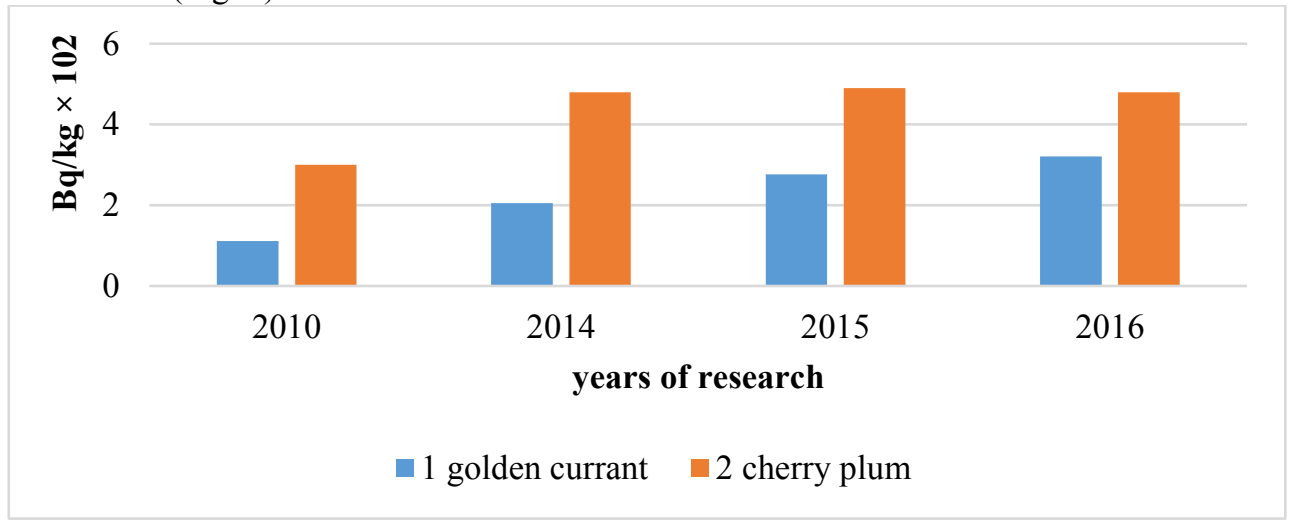

Fig. 2. Content of ${ }^{90} \mathrm{Sr}$ in the wood of the studied plants.

The difference in the accumulation of ${ }^{90} \mathrm{Sr}$ in the wood of Prunus cerasifera Ehrh and Ríbes aureum was established. According to the years of research $(2010,2014-2016)$, it is 
$2.7,2.3,1.8$, and 1.5 times, respectively. In general, a gradual decrease in differences in the accumulation of the nuclide in the wood of the studied plants can be noted. This fact can be explained by the different arrangement of the root system of cherry plum and golden currant in the soil over time. Shrub, unlike cherry plum, has a root system in the upper soil layer for a long time. The root system of cherry plum gradually goes deep into the soil, thereby reducing close contact with the nuclide located on the surface. Nevertheless, it should be noted that by 2016 , the cherry plum has accumulated more nuclide in the wood.

One of the most important plant organs is the leaf. Its functions are known, but there are no possible differences in the accumulation of ${ }^{90} \mathrm{Sr}$ depending on the species diversity of plants. Such studies have been performed, and the results are presented in Figure 3.

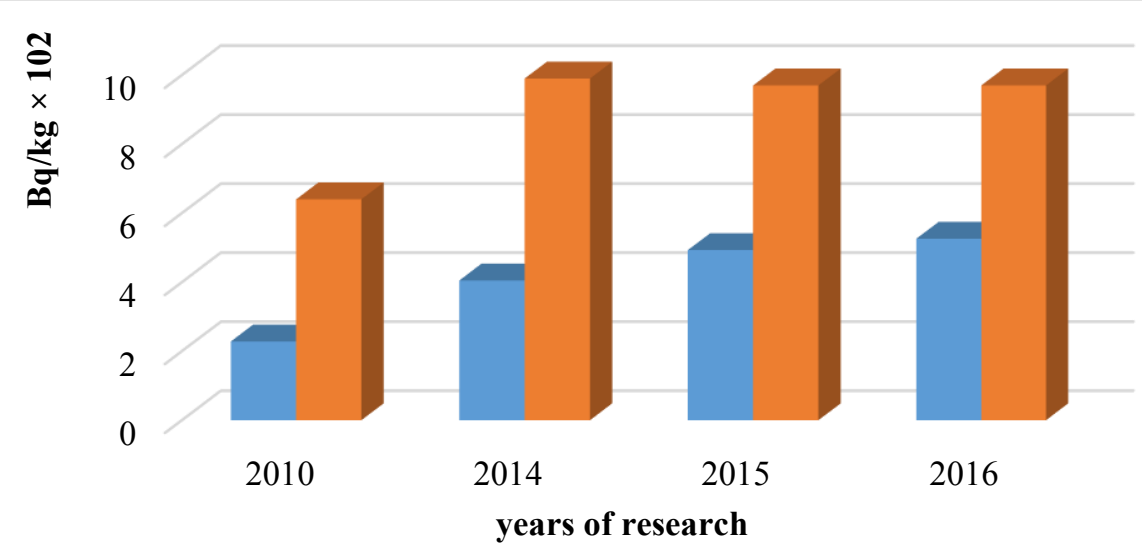

$\square 1$ golden currant $\quad \square$ cherry plum

Fig. 3. Content of ${ }^{90} \mathrm{Sr}$ in the leaves of the studied plants.

As a result of research, it was found that in the first period of growth and development in the studied area, the cherry plum leaves accumulated more of the studied radionuclide than the golden currant, the difference was 2.8 times. But by 2016, this difference is reduced and is 1.8 times. According to experimental data, it can be noted that, starting from 2014, there was practically no accumulation of ${ }^{90} \mathrm{Sr}$ in the bark, wood and leaves of cherry plum, unlike golden currant. The explanation of this "behavior" of a radionuclide and its accumulation in the vegetative organs of a plant can be found in the following: gradually over time the radionuclide turns into a less mobile form, but compared to ${ }^{137} \mathrm{Cs}$, it is still more mobile, a different location of the root system in the soil, as well as an increase in biomass of the plant itself.

One of the most important indicators for the accumulation of radionuclides in plants is its content in fruits (Fig. 4).

Fruits are used in food by humans, animals, birds, etc. Therefore, it is extremely important to know the radionuclide content in them. In the initial period of research (2010), a small $\left(0.30 \times 10^{2} \mathrm{~Bq} / \mathrm{kg}\right)$ content of it was found in the fruits of golden currant, which is 4.3 times less than in cherry plums. In the future, in the generative organs of the studied plants, a tendency in the accumulation of the radionuclide is observed, which is close to that of the vegetative organs. That is, in the initial period, the nuclide accumulates more intensively in the fruits of cherry plum, and then it decreases amid the continued accumulation of ${ }^{90} \mathrm{Sr}$ in the fruits of golden currant. 


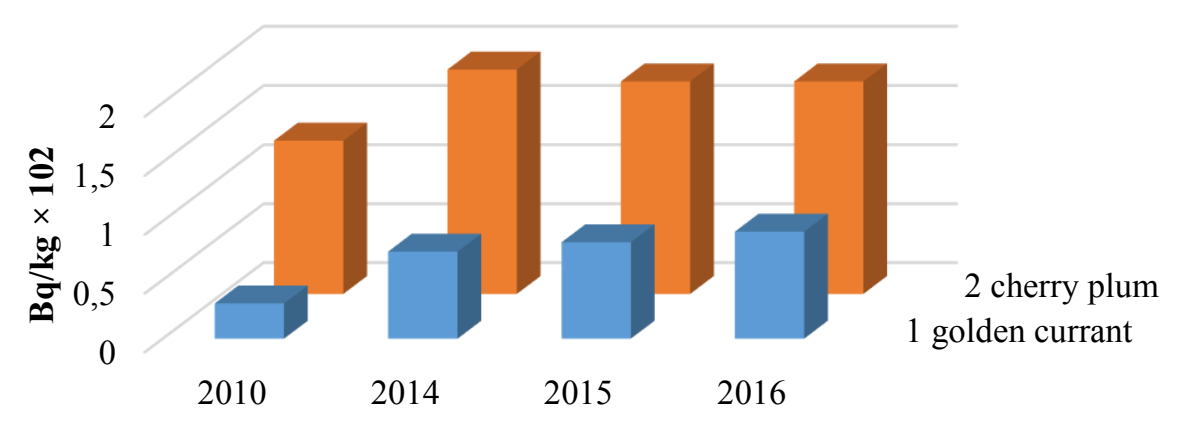

years of research

$\square 1$ golden currant $\quad \square 2$ cherry plum

Fig. 4. Content of ${ }^{90} \mathrm{Sr}$ in the fruits of the studied plants.

The difference in the radionuclide content in the fruits of cherry plum and golden currant by 2016 is already 2.0 times.

\section{Discussion}

With the surface location of the radionuclide on the soil, it is more found in the bark, wood, leaves, and fruits of cherry plum (Prunus cerasifera Ehrh) than golden currant (Ríbes aureum). One of the reasons for this difference in accumulation can be considered their biological difference. If in the initial period of growth and development of the studied plants, the same close contact of the root system with the radionuclide in the upper layer of soil is observed, then later, in the process of growth and development of the root system of cherry plum, its gradual penetration into the soil occurs. This fact undoubtedly influenced the nuclide content in the vegetative and generative organs of cherry plum. In the initial period of research, due to the more powerful root system, cherry plum has a greater intensity in the accumulation of nuclide, and there is a tendency to a decrease in its content in the studied plant organs. The dynamics of nuclide accumulation in the vegetative and generative organs of golden currant is completely different. Due to the fact that the root system is much longer in the upper soil layer, where ${ }^{90} \mathrm{Sr}$ is located, its accumulation continues throughout all period under the study.

\section{Conclusion}

In the initial period of growth and development, cherry plum (Prunus cerasifera Ehrh) accumulates radionuclide in vegetative and generative organs more intensively than golden currant (Ríbes aureum). According to experimental data, this woody plant can be most productively used to diagnose soil for radioactive contamination during this period. In the future, according to studies, the nuclide content in the studied organs of cherry plum is reduced. Nevertheless, it can be continued to be used as an indicator for the purpose of diagnosing the soil. Golden currant (Ríbes aureum) may also be of interest for the diagnosis of soil for radioactive contamination, but already in a more remote period after its entry into the soil. Therefore, both studied plants can participate in the diagnostics of areas allocated for the construction of public and industrial buildings, depending on the time of presence of 
nuclide in the soil. One should pay attention to the fact that the studied plants grow freely in the territory where the studied diagnostic method is recommended.

\section{References}

1. B.A. Dospekhov, Methodology of field test (Kolos, Moscow,1968)

2. Z.M. Lobanova, Ecology and biosphere protection: Study guide (Altai State Technical University Publishing House, Barnaul, 2009)

3. V.F. Valkov, K.Sh. Kazeev, S.I. Kolesnikov, Soil ecology: Soil pollution. A manual for students of biology-soil and geological-geographical faculties (Publishing House of RSU, Rostov-on-Don, 2004)

4. A.V. Khabarov, Socio-environmental problems of nature management, land use (Papyrus PRO, Moscow, 2000)

5. Yu.A. Sapozhnikov, R.A. Aliev, S.N. Kalmykov, Environmental radioactivity (BINOM, Laboratory of Knowledge, Moscow, 2006)

6. V.I. Bulatov, Radioactive Russia (CERIS, Novosibirsk, 1996)

7. K.P. Makhonko, Radiation situation on the territory of Russia and adjacent states in 1995 (NPO “Typhoon”, Obninsk, 1996)

8. V.G. Mikhalchenko, Healthcare of Belarus 6, 35-38 (1990)

9. F.I. Pavlotskaya, B.F. Myasoedov, Modern methods of separation and determination of radioactive elements 1, 36-45 (1989)

10. M.M. Golutvina, Yu.V. Abramov, Control over the intake and content of radioactive substances in the human body (Energoatomizdat, Moscow, 1989)

11. F.I. Pavlotskaya, E.V. Kuzovkina, T.A. Goryachenkova, Radiochemistry 39-5, 471475 (1997)

12. Y.A. Izrael, Health Physics 93-5, 410-417 (2007)

13. B. Luksiene, D. Marciulioniene, I. Gudeliene, Journal Of Environmental Radioactivity 116, 1-9 (2013)

14. A.I. Scheglov, Nature 4, 23-32 (2001)

15. N. Willey, K. Fawcett, Environmental And Experimental Botany 57-3, 258-269 (2006)

16. G. Zheng, R. Pemberton, P. Li, Chemistry And Ecology 33-1, 51-60 (2017)

17. Ye.A. Melchenko, V.A. Pogorelova, A.I. Melchenko, International Scientific and Practical Conference "Implementation of the methodological ideas of Professor B.A. Dospekhov in the improvement of adaptive landscape systems of agriculture (Moscow Timiryazev Agricultural Academy, Moscow, 2017)

18. Russian Federation Standard SP 47.13330.2012

19. A.I. Simakin, Agrochemical characteristics of the Kuban black soil and fertilizer (Krasnodar, 1969)

20. I.F. Garkusha, Soil science (Selkhozizdat, Moscow, 1962) 